\title{
Cloud optical depth retrievals from the Aerosol Robotic Network (AERONET) cloud mode observations
}

Article

Published Version

Chiu, J. C., Huang, C.-H., Marshak, A., Slutsker, I., Giles, D. M., Holben, B. N., Knyazikhin, Y. and Wiscombe, W. J. (2010) Cloud optical depth retrievals from the Aerosol Robotic Network (AERONET) cloud mode observations. Journal of Geophysical Research, 115 (D14). D14202. ISSN 0148-0227 doi: https://doi.org/10.1029/2009JD013121 Available at https://centaur.reading.ac.uk/16760/

It is advisable to refer to the publisher's version if you intend to cite from the work. See Guidance on citing.

Published version at: http://dx.doi.org/10.1029/2009JD013121

To link to this article DOI: http://dx.doi.org/10.1029/2009JD013121

Publisher: American Geophysical Union

All outputs in CentAUR are protected by Intellectual Property Rights law, including copyright law. Copyright and IPR is retained by the creators or other copyright holders. Terms and conditions for use of this material are defined in the End User Agreement. 


\section{CentAUR}

Central Archive at the University of Reading

Reading's research outputs online 


\title{
Cloud optical depth retrievals from the Aerosol Robotic Network (AERONET) cloud mode observations
}

\author{
J. Christine Chiu, ${ }^{1}$ Chiung-Huei Huang, ${ }^{2}$ Alexander Marshak, ${ }^{3}$ Ilya Slutsker, ${ }^{4}$ \\ David M. Giles, ${ }^{4}$ Brent N. Holben, ${ }^{3}$ Yuri Knyazikhin, ${ }^{5}$ and Warren J. Wiscombe ${ }^{3,6}$ \\ Received 31 August 2009; revised 22 January 2010; accepted 16 March 2010; published 17 July 2010.
}

[1] Cloud optical depth is one of the most poorly observed climate variables. The new "cloud mode" capability in the Aerosol Robotic Network (AERONET) will inexpensively yet dramatically increase cloud optical depth observations in both number and accuracy. Cloud mode optical depth retrievals from AERONET were evaluated at the Atmospheric Radiation Measurement program's Oklahoma site in sky conditions ranging from broken clouds to overcast. For overcast cases, the $1.5 \mathrm{~min}$ average AERONET cloud mode optical depths agreed to within 15\% of those from a standard ground-based flux method. For broken cloud cases, AERONET retrievals also captured rapid variations detected by the microwave radiometer. For 3 year climatology derived from all nonprecipitating clouds, AERONET monthly mean cloud optical depths are generally larger than cloud radar retrievals because of the current cloud mode observation strategy that is biased toward measurements of optically thick clouds. This study has demonstrated a new way to enhance the existing AERONET infrastructure to observe cloud optical properties on a global scale.

Citation: Chiu, J. C., C.-H. Huang, A. Marshak, I. Slutsker, D. M. Giles, B. N. Holben, Y. Knyazikhin, and W. J. Wiscombe (2010), Cloud optical depth retrievals from the Aerosol Robotic Network (AERONET) cloud mode observations, J. Geophys. Res., 115, D14202, doi:10.1029/2009JD013121.

\section{Introduction}

[2] Cloud optical depth is the most fundamental cloud property determining the Earth's radiative energy balance. However, cloud optical depth is poorly predicted by climate models [Zhang et al., 2005; Bender et al., 2006] and is very difficult to remotely sense from the surface using traditional methods [Turner et al., 2007]. A dramatic increase in both the number and accuracy of cloud optical depth observations is crucial both for validation and improvement of climate model predictions.

[3] While a number of satellites routinely observe clouds, measurements from ground-based networks are limited. We are aware of only two operational networks that provide continuous cloud measurements: one is the Atmospheric Radiation Measurement (ARM) program [Stokes and Schwartz, 1994], and the other is Cloudnet [Illingworth et al., 2007]. The former has five sites in Oklahoma, Alaska, and the tropical western Pacific region, and the latter has three sites in the United Kingdom, France, and

\footnotetext{
USA.

${ }^{1}$ University of Maryland Baltimore County, Baltimore, Maryland,

${ }^{2}$ Science Systems and Applications, Inc., Lanham, Maryland, USA.

${ }^{3}$ NASA/Goddard Space Flight Center, Greenbelt, Maryland, USA.

${ }^{4}$ Sigma Space Corporation, Lanham, Maryland, USA.

${ }^{5}$ Boston University, Boston, Massachusetts, USA.

${ }^{6}$ Brookhaven National Laboratory, New York, New York, USA.
}

Copyright 2010 by the American Geophysical Union. 0148-0227/10/2009JD013121
Netherlands. Thus, ground-based cloud observations on a global scale are nearly absent.

[4] The Aerosol Robotic Network (AERONET) is a ground-based network that is designed to measure microphysical and optical properties of aerosols [Holben et al., 1998]. AERONET is composed of Sun/sky radiometers with a $1.2^{\circ}$ field-of-view (FOV) that measure radiance at wavelengths of 440, 675, 870, and $1020 \mathrm{~nm}$. Direct Sun measurements are mainly used to screen out clouds and to retrieve aerosol optical depth, while sky radiance measurements are mainly used to retrieve aerosol microphysical and optical properties such as aerosol size distribution, phase function, and single scattering albedo. AERONET aerosol retrievals, available at more than 250 sites, have been extensively used to quantify aerosol direct and indirect effects, validate satellite aerosol retrievals, and develop aerosol forecast models [e.g., Levy et al., 2007; Morcrette et al., 2009; Andreae, 2009; Myhre et al., 2009].

[5] When clouds completely block the Sun, direct Sun and sky measurements are not appropriate for retrieving aerosol optical properties. In these situations, the radiometer is placed into sleep mode. As a result, we propose to use some of this idle time to observe clouds. We shall call the traditional mode for monitoring aerosols "normal aerosol mode," and the new one for monitoring clouds, "cloud mode." In cloud mode, AERONET radiometers point directly up (i.e., zenith) and perform 10 zenith radiance measurements at $9 \mathrm{~s}$ intervals for each wavelength, which are obtained by successively rotating an interference filter in front of the detector. 


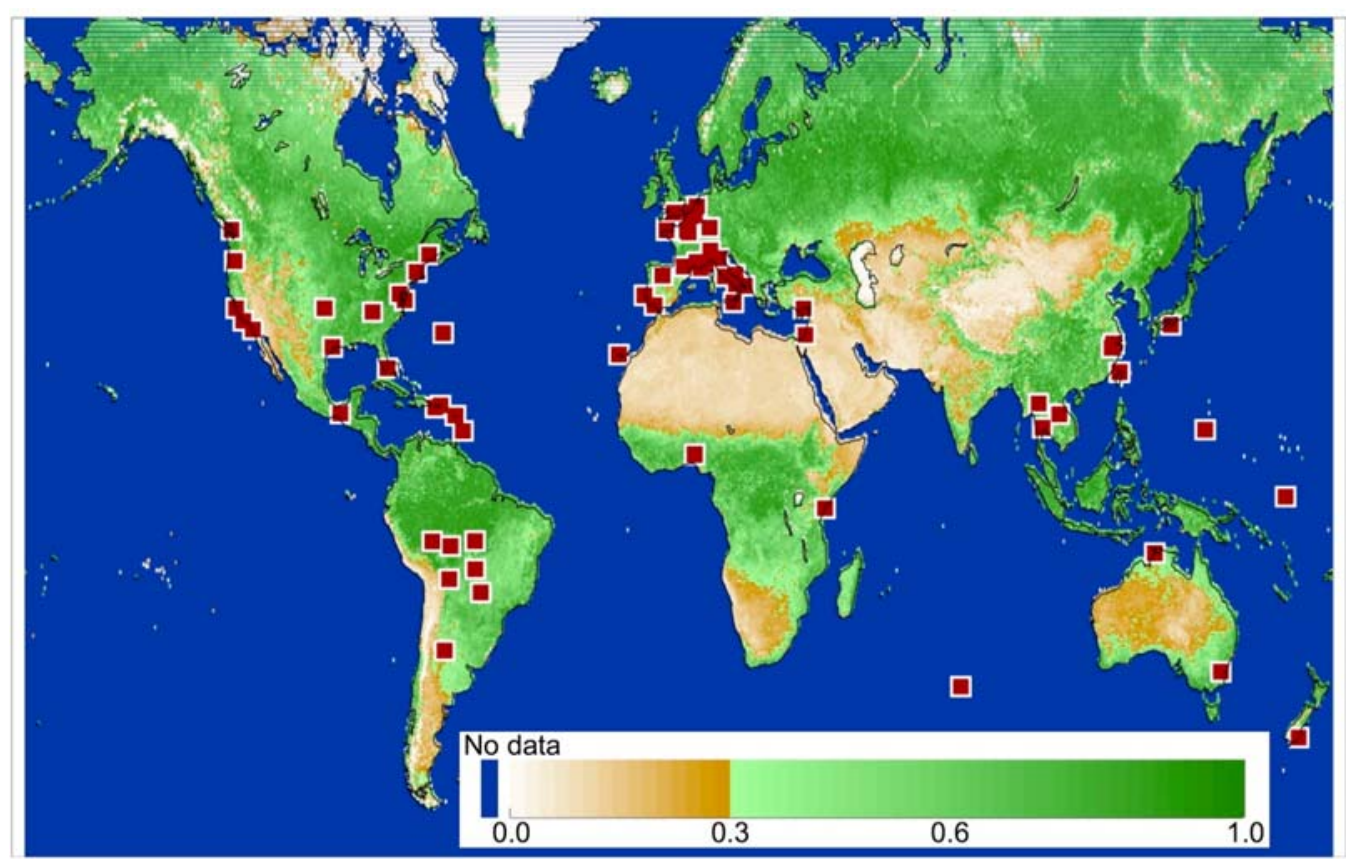

Figure 1. Normalized difference vegetation index (NDVI) from MODIS/Aqua measurements during 18 June to 3 July 2007. Red dots show AERONET sites where 95\% NDVI values were greater than 0.3 for years 2005-2008. Note that only AERONET sites operated in both year 2007 and 2008 are considered here.

[6] This paper presents cloud optical depth retrievals from AERONET cloud mode measurements. In section 2, we describe how cloud mode sites will be selected. We also briefly review our retrieval method and describe cloud products that will be available via the AERONET Web site. In section 3, we compare our retrieved cloud optical depths with those from ARM and the Moderate Resolution Imaging Spectroradiometer (MODIS). Finally, section 4 summarizes this paper.

\section{AERONET Cloud Products}

\subsection{Cloud Mode Site Selection}

[7] Marshak et al. [2000] and Barker and Marshak [2001] suggested using measurements at $673 \mathrm{~nm}$ (RED) and $870 \mathrm{~nm}$ (near-infrared (NIR)) wavelengths to retrieve cloud optical depth over a vegetated surface with ground-based measurements, while Barker et al. [2002] applied a similar method to aircraft measurements. These two wavelengths were used to capture the variability in surface reflectance over this wavelength region, where cloud optical properties are nearly identical. This vegetated surface reflectance, which increases by a factor of approximately 5 between 440 and $870 \mathrm{~nm}$, was essential for providing robust retrievals. A similar retrieval method for AERONET cloud mode observations is proposed in this study, and potential cloud mode sites were chosen based on the spectral contrast in surface reflectance.

[8] The spectral contrast in surface reflectance is evaluated by a normalized difference vegetation index (NDVI), a ratio of the reflectance difference between RED and NIR wavelengths to their sum [Tucker, 1979]. An example of NDVI global map is shown in Figure 1, which uses MODIS/ Aqua 16 day vegetation index products (collection 5). In general, a larger NDVI value corresponds to more developed green vegetation and thus greater spectral contrast. Chiu et al. [2006] concluded that NDVI values lower than 0.4 were not ideal but sufficient for their retrieval method. In this paper we use a NDVI threshold of 0.3 for selections of cloud mode sites (as explained in section 2.2). We then calculated the fraction of NDVI value greater than 0.3 during year 2005-2008 for each AERONET site. A site will be operated in cloud mode if NDVI around the site is greater than 0.3 for $95 \%$ of time. Based on these criteria, 71 sites were identified as potential cloud mode sites (Figure 1).

\subsection{Cloud Mode Retrieval Method}

[9] Cloud optical depth is impossible to unambiguously retrieve from only single-wavelength measurements because zenith radiance lacks a one-to-one relationship with cloud optical depth (see Figure 2 in the study of Marshak et al. [2004]). To reduce the retrieval ambiguity, Marshak et al. [2004] and Chiu et al. [2006] used zenith radiances at $673 \mathrm{~nm}$ and $870 \mathrm{~nm}$ wavelengths to simultaneously retrieve optical depth and effective cloud fraction over a vegetated surface. As previously mentioned, these two wavelengths were selected because of a spectral contrast in surface reflectance. Alternatively, Kikuchi et al. [2006] used zenith radiances at water-absorbing and nonabsorbing wavelengths to retrieve cloud optical depth and drop effective radius.

[10] The proposed retrieval method for AERONET cloud mode observations, similar to the study of Marshak et al. 


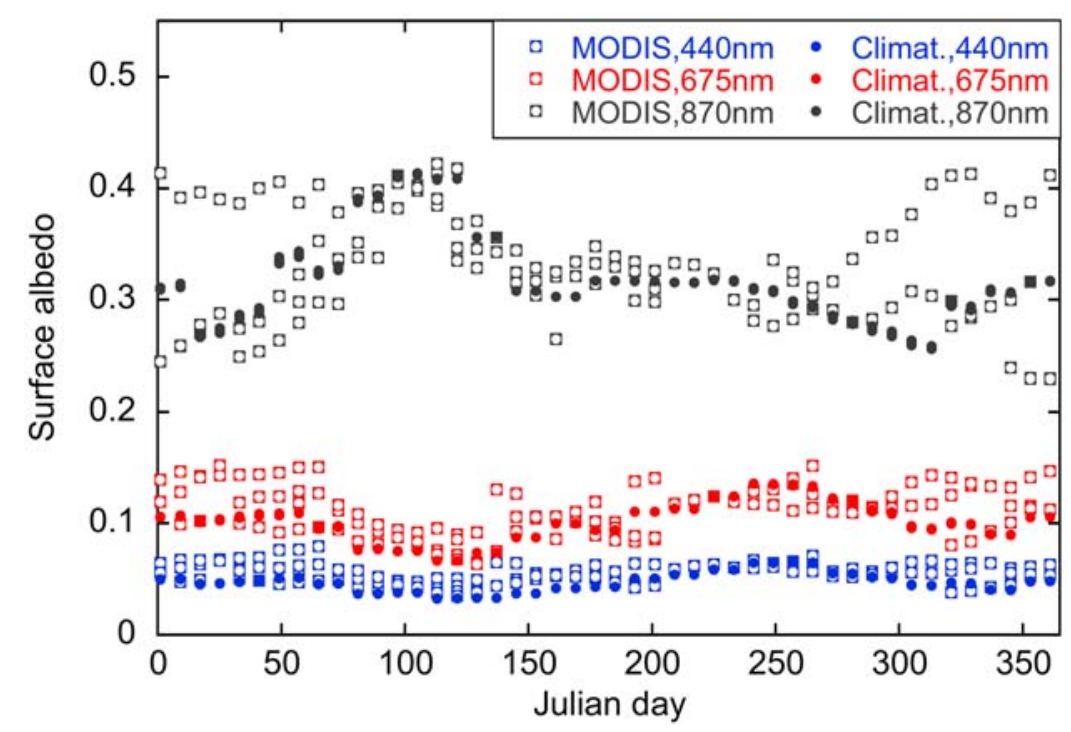

Figure 2. Surface albedo values at wavelengths of 440, 675, and $870 \mathrm{~nm}$ at the ARM Oklahoma site, which were estimated from MODIS Terra/Aqua combined products during November 2004 to June 2008 and the AERONET climatological database. (For spectral surface albedo estimated from ground-based measurements, see Figure 5 in the study of $\mathrm{Li}$ et al. [2002].)

[2004], is briefly reviewed here. For plane-parallel clouds over a Lambertian surface, any ground-based measurement of radiance $I$ can be approximated as

$$
I_{\lambda}\left(\tau_{\mathrm{c}}, A_{\mathrm{c}}\right)=I_{0, \lambda}\left(\tau_{c}\right)+\frac{\rho_{\lambda} I_{\mathrm{s}, \lambda}\left(\tau_{\mathrm{c}}\right) \cdot\left[1-A_{\mathrm{c}}+A_{\mathrm{c}} T_{0, \mathrm{pp}, \lambda}\left(\tau_{\mathrm{c}}\right)\right]}{1-\rho_{\lambda} R_{\lambda}\left(\tau_{\mathrm{c}}\right)}
$$

[Box et al., 1988; Marshak et al., 2004], where the subscript $\lambda$ is wavelength, $\tau_{\mathrm{c}}$ is cloud optical depth, and $A_{\mathrm{c}}$ is effective cloud fraction. The first term on the right hand side, $I_{0, \lambda}$, is downward radiance calculated over a nonreflecting (black) surface, while the second term is radiation introduced by interactions between clouds and the underlying surface. The cloud-surface interactions are fully determined by $\rho_{\lambda}, A_{\mathrm{c}}$, $I_{\mathrm{s}, \lambda}, T_{0, \mathrm{pp}, \lambda}$, and $R_{\lambda}$, where $\rho_{\lambda}$ is the albedo of the underlying surface, $T_{0, p p, \lambda}$ is the total transmittance of monochromatic radiation over a black surface in a plane-parallel assumption, $I_{\mathrm{s}, \lambda}$ is the downward radiance generated by an isotropic source $1 / \pi$ located at the surface, and $R_{\lambda}$ is the spherical cloud albedo given uniform, isotropic illumination from below. To calculate $I_{\lambda}$ from equation (1) over a reasonable range of $\tau_{\mathrm{c}}$ and $A_{\mathrm{c}}$, we used the discrete-ordinate-method radiative transfer model [Stamnes et al., 1988], assuming an $8 \mu \mathrm{m}$ effective radius (see section 3.1).

[11] Surface albedo, $\rho_{\lambda}$, is estimated from two data sets: (1) collection 5 products from MODIS Terra/Aqua combined data at $500 \mathrm{~m}$ resolution [Schaaf et al., 2002] and (2) an optimized climatological database derived from year 2000-2004, 16 day average MODIS surface reflectivity product at $1 \mathrm{~min}$ resolution [Moody et al., 2005, 2007]. Figure 2 shows surface albedo estimates from both data sets over the ARM Oklahoma site. The plot shows that the surface is the darkest at $440 \mathrm{~nm}$ and surface albedo has a large increase between 675 and $870 \mathrm{~nm}$, which confirms the spectral contrast required in our retrieval method. In addition, MODIS 16 day surface albedo values available every 8 days have significant annual variations, especially at 675 and $870 \mathrm{~nm}$. The climatological database has a similar seasonal variation to MODIS albedo, but the climatology obviously does not capture annual variability based on the 2000-2004 period. For operational processing, we will first check the availability of the MODIS surface reflectance product. If the MODIS product is not available, we use surface reflectivity parameters from the climatological database. Operationally, the climatological surface albedo is also modified daily using MODIS collection 5 snow products to account for snow cover effects where appropriate during the wintertime [Hall et al., 2002].

[12] The nonnegligible annual variability at $675 \mathrm{~nm}$ wavelength leads to the following modification in our retrieval method. Unlike the two-channel radiometer used in the study of Chiu et al. [2006], as stated previously, AERONET radiometers measure at four radiance wavelengths. We found that the $440 \mathrm{~nm}$ wavelength has a unique advantage over $675 \mathrm{~nm}$ as most vegetated surfaces are darker at $440 \mathrm{~nm}$ (as shown in Figure 2), and it provides an even larger contrast to $870 \mathrm{~nm}$. The improved contrast in surface reflectance allows the use of a lower threshold for NDVI (0.3) in the selection of cloud mode sites (as mentioned in section 2.1) and assures retrieval stability. Therefore, our method is less sensitive to the uncertainty in surface albedo estimates as shown in Figure 3.

[13] Figure 3 shows model-generated lookup tables and a few cloud mode measurements on 20 January 2006. Figures $3 \mathrm{a}$ and $3 \mathrm{~b}$ are calculated using surface albedo estimates from MODIS and the climatological albedo database, respectively. The underlying lines correspond to cloud optical depth $\left(\tau_{\mathrm{c}}\right)$ ranging from 0 to 90 , while the curves corresponding to effective cloud fractions $\left(A_{\mathrm{c}}\right)$ ranging from 

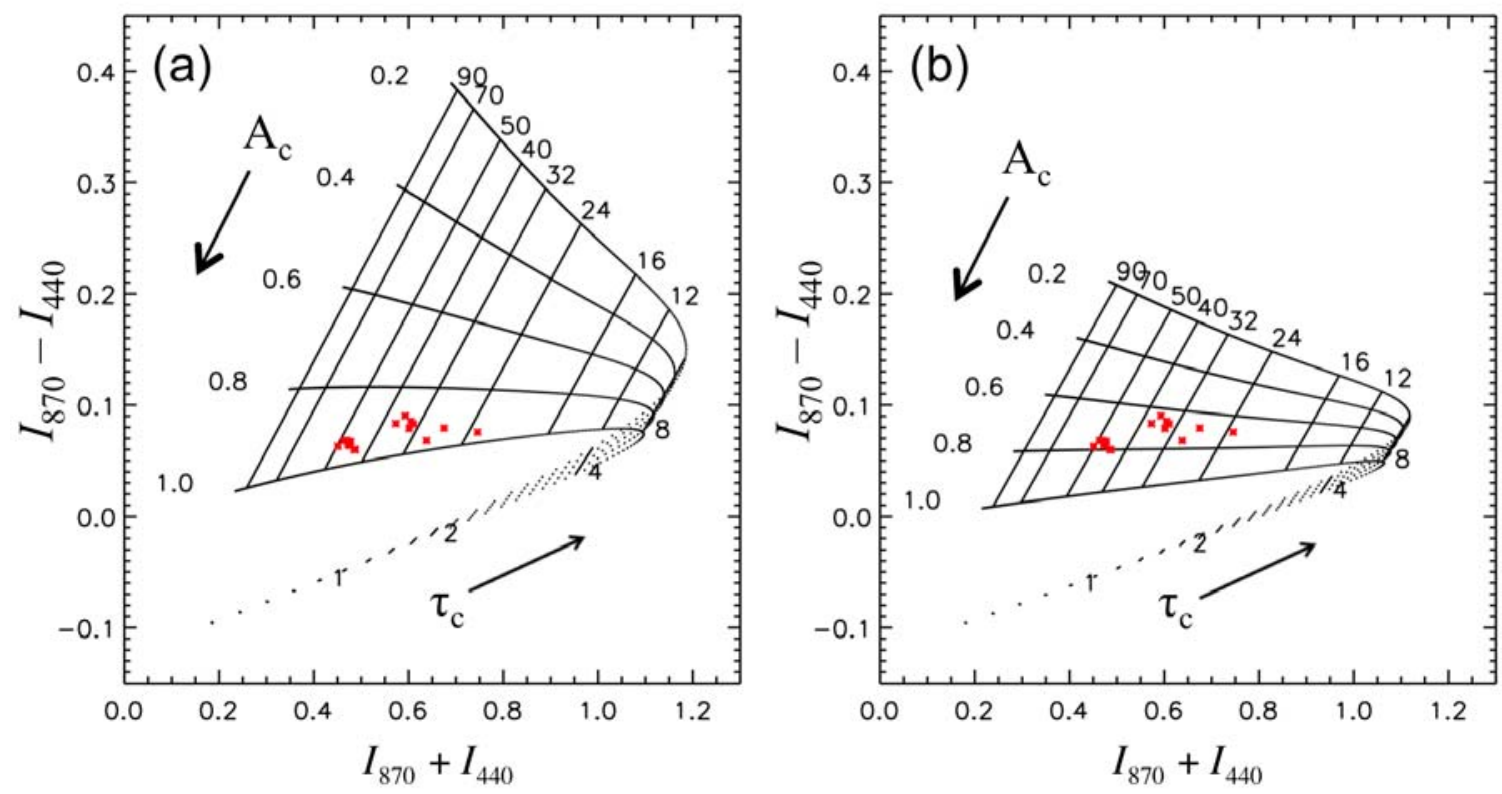

Figure 3. Model-generated lookup tables assuming a cloud effective radius of $8 \mu \mathrm{m}$ and solar zenith angle of $58^{\circ}$. Surface albedo values at 440 and $870 \mathrm{~nm}$ are (a) 0.06 and 0.40 (from MODIS products) and (b) 0.05 and 0.27 (from the climatology database). Lines and curves represent various cloud optical depth $\left(\tau_{\mathrm{c}}\right)$ and effective cloud fraction $\left(A_{\mathrm{c}}\right)$, respectively. Red dots are data points taken from AERONET cloud mode operation at the ARM Oklahoma site on 20 January 2006.

0.2 to 1.0. Red dots are cloud mode data points. By coplotting data points on the underlying lines, we can retrieve both $\tau_{\mathrm{c}}$ and $A_{\mathrm{c}}$ simultaneously.

[14] The two sets of surface albedo used in Figure 3 have a difference of $15 \%$ at $440 \mathrm{~nm}$ and $30 \%$ at $870 \mathrm{~nm}$, while the absolute spectral contrasts for MODIS and climatological data are 0.34 and 0.22 , respectively. When the spectral contrast is reduced from Figure $3 \mathrm{a}$ to Figure $3 \mathrm{~b}$, the underlying curves shrink, and thus, retrieved cloud fractions $A_{\mathrm{c}}$ are affected significantly; however, the impact on cloud optical depth retrievals is small. Therefore, retrieved $\tau_{\mathrm{c}}$ is much less sensitive to the uncertainty in surface albedo than $A_{\mathrm{c}}$. This is a new and important feature for our retrieval method and has not been reported in earlier studies of sensitivity to uncertainty in surface albedo [Barker and Marshak, 2001; Marshak et al., 2004; Chiu et al., 2006].

[15] The three main sources of uncertainty for our retrievals include zenith radiance measurements, assumed cloud drop effective radius, and surface albedo estimates. At given surface albedo values of 0.05 and 0.3 at 440 and $870 \mathrm{~nm}$, respectively, $5 \%$ uncertainty in zenith radiance measurements leads to a 5\%-10\% error in retrieved cloud optical depth, while $25 \%$ uncertainty in cloud drop effective radius leads to a $\sim 4 \%$ error. When uncertainty in surface albedo is assumed to be $10 \%$ and $5 \%$ for 440 and $870 \mathrm{~nm}$, respectively, retrievals have a $1 \%-3 \%$ error. Based on these sources of uncertainty, the total retrieved cloud optical depth uncertainty is expected to be up to $17 \%$. Although uncertainty in aerosol loading also causes errors in our cloud optical depth retrievals, these errors are negligible because the majority of retrieved cloud optical depths are larger than 15 (as shown in section 3).

\subsection{Cloud Mode Optical Depth Averaging Technique}

[16] Two types of cloud optical depth retrievals are presented in this paper: instantaneous and $1.5 \mathrm{~min}$ average. The former is retrieved from zenith measurements every $9 \mathrm{~s}$ at each wavelength giving at most 10 values every $15 \mathrm{~min}$ during cloud mode operation. These values are grouped into a cluster spanning a $\sim 1.5 \mathrm{~min}$ time interval. (With a nominal wind speed of $10 \mathrm{~m} \mathrm{~s}^{-1}$, a cluster corresponds to $\sim 1 \mathrm{~km}$.) The problem is how to create a meaningful average of cloud optical depth over this time interval, excluding as many as possible clear sky occurrences.

[17] To reduce combined impacts of cloud gaps and unphysical retrievals on the cluster's average, we exclude retrievals below the 25th and above the 50th percentile (a similar approach was used by Remer et al. [2005] for aerosol retrievals). Typically, this "exclusion method" means we average only 2 or 3 of the (maximum) 10 points in the cluster. A certain arbitrariness results here, we could have chosen other numbers than 25 and 50 , but after considerable experimentation, empirically, the 25 th to 50 th percentile averages were accepted to represent our $1.5 \mathrm{~min}$ average cloud optical depths.

[18] We chose this exclusion method for two reasons. The first reason is the radiative effect of a finite FOV. When a cloud is fragmented, instantaneous retrievals suffer from the "clear-sky contamination" problem [Chiu et al., 2006]. This problem occurs when the radiometer FOV is partially clear, which causes smaller zenith radiances than if the FOV were fully cloudy. This condition leads to unphysically large cloud optical depth retrievals. These unphysical retrievals would significantly bias the mean toward large values. The second reason for using the exclusion method is that a few 

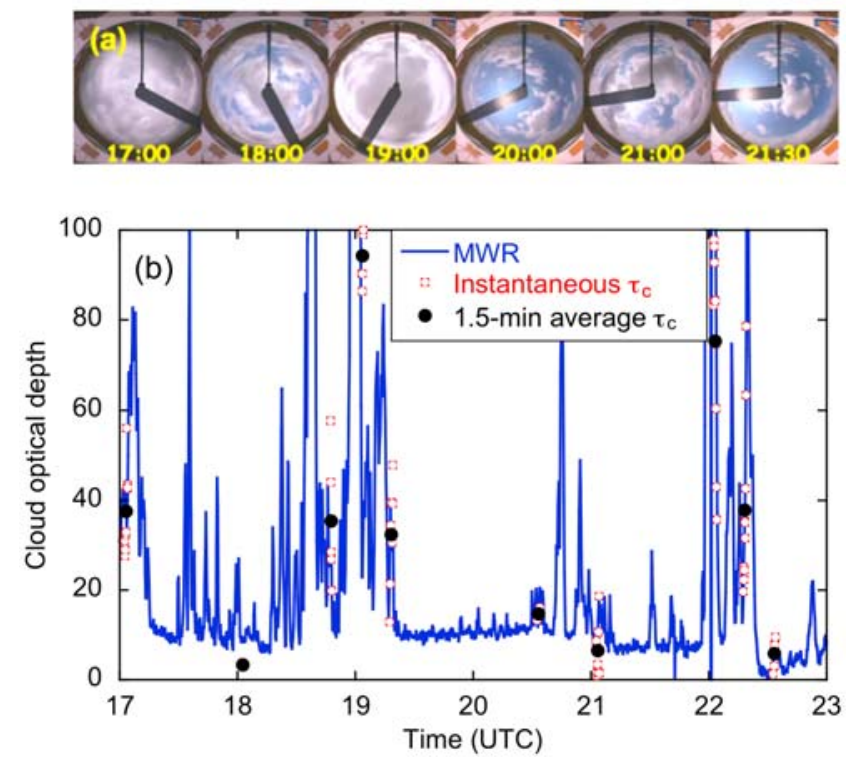

Figure 4. A broken cloud case at the ARM Oklahoma site on 15 June 2007. (a) Total sky images. (b) Retrieved cloud optical depth. Blue lines are retrievals from the ARM microwave radiometer assuming an $8 \mu \mathrm{m}$ droplet effective radius. Red and black dots represent AERONET instantaneous and 1.5 min average cloud optical depths.

data points may be associated with small clear-sky values retrieved in cloud gaps. Here the situation is opposite to the first reason because we need to remove unphysically small rather than unphysically large values of cloud optical depth.

[19] The exclusion method is essential for broken clouds. And for overcast clouds, the method will not change the average cloud optical depth significantly (less than 4\%) when compared to the cloud optical depth calculated from all points in the cluster.

\section{Comparison of AERONET Cloud Products to ARM and MODIS Observations}

[20] Cloud optical depths retrieved from AERONET were compared to cloud products from the Atmospheric Radiation Measurement (ARM) program and MODIS. Among the ARM sites, the Oklahoma site is the largest and most extensive climate research field site. This site has established long-term cloud observations since 1992. To take advantage of these data, we focused our intercomparison on the ARM Oklahoma site and provided analyses of three example periods: (1) a broken-cloud case, (2) overcast cases in 2007, and (3) 3 year climatology.

\subsection{Broken Cloud Case}

[21] For broken clouds, AERONET cloud optical depths are intercompared to those inferred from the ARM microwave radiometer (MWR). The MWR (with a $5.9^{\circ} \mathrm{FOV}$ ) provides $1 \mathrm{~s}$ average brightness temperatures at 23.8 and $31.4 \mathrm{GHz}$ and liquid water path (LWP) retrievals every $20 \mathrm{~s}$ [Liljegren and Lesht, 1996; Liljegren et al., 2001]. Uncertainties in LWP retrievals are $\sim 20-30 \mathrm{gm}^{-2}$ [Liljegren and Lesht, 1996; Westwater et al., 2001; Marchand et al.,
2003; Crewell and Löhnert, 2003]. From LWP, we calculated cloud optical depth $\left(\tau_{\mathrm{c}}\right)$ at visible wavelengths using

$$
\tau_{\mathrm{c}}=\frac{3(\mathrm{LWP})}{2 \rho_{\mathrm{w}} r_{\mathrm{eff}}},
$$

where LWP is in units of $\mathrm{gm}^{-2}$ and $\rho_{\mathrm{w}}$ is the density of water. Droplet effective radius is assumed to be $8 \mu \mathrm{m}$, which is typical for the Oklahoma site [Kim et al., 2003; Sengupta et al., 2003].

[22] Figure 4a show images taken from the ARM total sky imager (TSI) on 15 June 2007. In TSI images, a shadowband on the mirror blocks the intense direct normal light from the Sun. Clouds of interest are located at the center of the images showing changes between scattered cumulus and relatively dark overcast clouds. For such complex cloud fields, AERONET retrievals show good agreement with MWR values (Figure 4b); however, we found that current AERONET cloud mode operation favors observing thicker clouds. Evidence for this finding is that no cloud mode measurement was made during 1930-2030 and 21152200 UTC even though scattered cumuli were around (as shown in TSI images). These cumuli have 5-10 cloud optical depth based on MWR retrievals, which indicates that such optical depth values are likely missed in AERONET cloud mode retrievals under the current observation strategy.

\subsection{Overcast Cloud Case Analysis}

\subsubsection{Comparison to MFRSR Retrievals}

[23] For overcast clouds, ground-based flux measurements have been widely used to retrieve cloud optical depth. The ARM multifilter rotating shadowband radiometer (MFRSR), with a hemispheric FOV, provides $20 \mathrm{~s}$ averages of both direct and diffuse solar flux in narrow bands centered at $415,500,615,673,870$, and $940 \mathrm{~nm}$. To minimize surface reflectance uncertainty, we used direct and diffuse transmittance at $415 \mathrm{~nm}$, together with 1-D radiative transfer theory, to retrieve cloud optical depth. Our flux method is similar to the one proposed by Min and Harrison [1996].

[24] Overcast cases were objectively selected using the following criteria. When MFRSR retrievals were found continuously greater than 5 for at least $1 \mathrm{~h}$, we defined the time period as overcast. The AERONET radiometers have a wetness sensor to prevent water contamination of the sensor window, so cloud mode-cloud mode observations are made during precipitation-free periods. However, this condition does not guarantee that the MFRSR dome in the same periods was free of rain contamination. Therefore, we checked rain gauge data and excluded rainy periods. As a result, we found a total of 170 nonprecipitating, overcast cases in year 2007.

[25] A scatter plot of instantaneous cloud optical depths retrieved from AERONET versus those from MFRSR is shown in Figure 5a. The majority of retrieval pairs are close to the $1: 1$ line. We found that more than $60 \%$ of retrievals agree within $20 \%$. The mean and standard deviation of cloud optical depths from the two instruments are close; the differences in mean and standard deviation are both around one optical depth. The average relative error is around $20 \%$, and the correlation is 0.86 . We also compare AERONET $1.5 \mathrm{~min}$ average retrievals with MFRSR $1.5 \mathrm{~min}$ averages in Figure $5 \mathrm{~b}$. Results show that the average relative error is around $15 \%$, and the correlation is 0.92 . Overall, for over- 

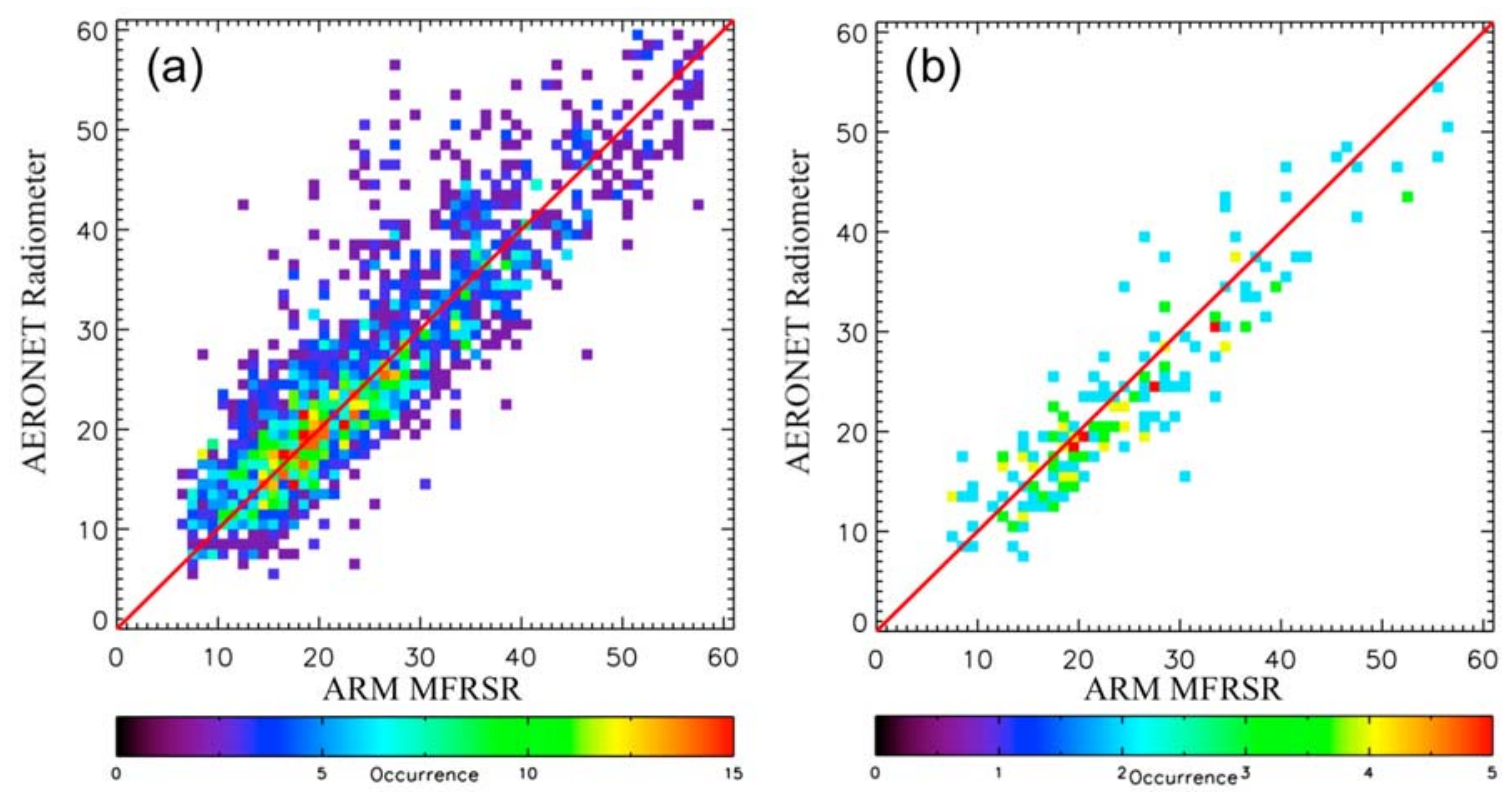

Figure 5. Scatter plots of (a) instantaneous and (b) $1.5 \mathrm{~min}$ average cloud optical depth retrievals from the AERONET radiometers versus the ARM MFRSR for all overcast cases in 2007. The number of occurrences is represented by the color bar.

cast cases, our AERONET 1.5 min average cloud optical depths agree well with those from fluxes. Results are satisfying because these two methods use completely different radiative quantities (hemispherical flux versus pointwise zenith radiance) to retrieve cloud optical depth.

\subsubsection{Comparison to MODIS Retrievals}

[26] In this section, we compare AERONET $1.5 \mathrm{~min}$ average cloud optical depth retrievals to MODIS level 2 cloud products (collection 5) for those 170 nonprecipitating, overcast cases. For intercomparison between ground- and satellite-based data, one needs to determine two things: the time window of interest and the number of satellite pixels averaged over the site. To maximize the number of AERONET sample points, we need a longer time window. However, to avoid using too many MODIS pixels (which would tend to invalidate the hypothesis that time and space averages are interchangeable), a shorter time window is preferable. As a result, we compromised on a $1 \mathrm{~h}$ time window centered at the MODIS overpass time.

[27] To determine the number of satellite pixels, we need to know where clouds are and what the wind is at cloud base. Cloud location at $10 \mathrm{~s}$ resolution is given by the ARM Active Remotely Sensed Clouds Locations data product [Clothiaux et al., 2000], and wind speed at 1 min resolution is given by the ARM Merged Sounding data product [Miller et al., 2003]. For each time window, we binned cloud base heights into $200 \mathrm{~m}$ bins and then calculated the average cloud base height from the mode (i.e., the bin with the highest frequency of cloud base heights). The mean wind speed at the average cloud base height was then used to calculate the appropriate number of MODIS pixels.

[28] MODIS provides cloud phase and optical depth at $1 \mathrm{~km}$ resolution. We selected overpasses when the distance between the ARM site and the closest pixel was less than $2 \mathrm{~km}$. In addition, we used MODIS retrievals only when their corresponding cloud phase is liquid water. As a result,
28 overpasses remain in which retrievals from AERONET cloud mode and MODIS are simultaneously available: 14 from Terra and 14 from Aqua. Detailed information for each overpass is given in Tables 1 and 2 .

[29] Figure 6 compares our AERONET and MODIS optical depth retrievals for each overpass. The AERONET values (up to 4 points) are represented by filled circles while the statistics of the MODIS values are represented by box plots (the definition of the box plot is given in the figure caption). Figure 6 shows two important results. First, even for overcast cases, MODIS optical depths give evidence of substantial cloud inhomogeneity. Second, $70 \%-80 \%$ of AERONET retrievals fall into the MODIS "acceptable range." These results, while they show the sometimes

Table 1. Data From 14 Overcast Cases in 2007 Used in Comparing Cloud Optical Depth From Ground-Based Measurements to MODIS/ Terra Overpasses

\begin{tabular}{ccccc}
\hline $\begin{array}{c}\text { Overpass } \\
\text { Index }\end{array}$ & $\begin{array}{c}\text { Date in } \\
2007\end{array}$ & $\begin{array}{c}\text { Time } \\
(\mathrm{UTC})\end{array}$ & $\begin{array}{c}\text { Cloud Base }_{\text {Height }^{\mathrm{a}}(\mathrm{m})} \\
1\end{array}$ & $\begin{array}{c}\text { Wind Speed } \\
(\mathrm{m} / \mathrm{s})\end{array}$ \\
\hline 2 & $15 \mathrm{May}$ & 1740 & 880 & 14.3 \\
3 & $26 \mathrm{May}$ & 1720 & 1185 & 8.6 \\
4 & $25 \mathrm{Aug}$ & 1705 & 720 & 5.5 \\
5 & $5 \mathrm{Sep}$ & 1645 & 1520 & 8.7 \\
6 & $14 \mathrm{Sep}$ & 1640 & 1080 & 6.8 \\
7 & $15 \mathrm{Sep}$ & 1725 & 690 & 8.1 \\
8 & $10 \mathrm{Nov}$ & 1635 & 150 & 5.7 \\
9 & $10 \mathrm{Nov}$ & 1810 & 150 & 5.7 \\
10 & $21 \mathrm{Nov}$ & 1755 & 490 & 13.9 \\
11 & $25 \mathrm{Nov}$ & 1730 & 2435 & 6.7 \\
12 & 8 Dec & 1700 & 105 & 5.8 \\
13 & $12 \mathrm{Dec}$ & 1635 & 3510 & 25.5 \\
14 & $12 \mathrm{Dec}$ & 1810 & 3510 & 25.0 \\
\hline
\end{tabular}

${ }^{\text {a} E s t i m a t e d ~ f r o m ~ A R M ' s ~ A c t i v e ~ R e m o t e l y ~ S e n s e d ~ C l o u d s ~ L o c a t i o n s ~}$ (ARSL) product.

${ }^{\mathrm{b}}$ Estimated from ARM's Merged Sounding product. 
Table 2. Data From 14 Overcast Cases in 2007 Used in Comparing Cloud Optical Depth From Ground-Based Measurements to MODIS/ Aqua Overpasses

\begin{tabular}{|c|c|c|c|c|}
\hline $\begin{array}{l}\text { Overpass } \\
\text { Index }\end{array}$ & $\begin{array}{c}\text { Date in } \\
2007\end{array}$ & $\begin{array}{l}\text { Time } \\
\text { (UTC) }\end{array}$ & $\begin{array}{l}\text { Cloud Base } \\
\text { Height }^{\mathrm{a}}(\mathrm{m})\end{array}$ & $\begin{array}{c}\text { Wind Speed } \\
(\mathrm{m} / \mathrm{s})\end{array}$ \\
\hline 1 & 5 May & 2020 & 1480 & 20.5 \\
\hline 2 & 20 June & 1855 & 1145 & 5.4 \\
\hline 3 & 8 Sep & 1855 & 3920 & 3.9 \\
\hline 4 & $10 \mathrm{Sep}$ & 2020 & 1080 & 7.8 \\
\hline 5 & $14 \mathrm{Oct}$ & 2005 & 1260 & 13.3 \\
\hline 6 & 12 Nov & 1935 & 1440 & 8.7 \\
\hline 7 & $21 \mathrm{Nov}$ & 1930 & 1440 & 14.0 \\
\hline 8 & 30 Nov & 1925 & 1460 & 12.8 \\
\hline 9 & $6 \mathrm{Dec}$ & 1850 & 700 & 10.7 \\
\hline 10 & $6 \mathrm{Dec}$ & 2025 & 720 & 11.3 \\
\hline 11 & $8 \mathrm{Dec}$ & 2015 & 105 & 5.1 \\
\hline 12 & $12 \mathrm{Dec}$ & 1950 & 3900 & 30.7 \\
\hline 13 & $13 \mathrm{Dec}$ & 1855 & 3900 & 17.4 \\
\hline 14 & $14 \mathrm{Dec}$ & 1935 & 106 & 5.3 \\
\hline
\end{tabular}

${ }^{a}$ Estimated from ARM's Active Remotely Sensed Clouds Locations (ARSL) product.

${ }^{\mathrm{b}}$ Estimated from ARM's Merged Sounding product.

frustrating difficulty of comparing satellite and surface retrievals, are quite encouraging considering that there are only a maximum of 4 AERONET retrievals in a $1 \mathrm{~h}$ time period. If AERONET cloud mode observations were made more frequently, we are confident that the comparison would show better agreement.

[30] AERONET retrievals have significant departures from MODIS retrievals for Terra overpass 1, 2, 6, and 8 (Figure 6a) and for Aqua overpass 1, 2, and 10 (Figure 6b). For these overpasses, we investigated whether the large AERONET optical depth values are reasonable. Because MWR microwave data are not available for Terra overpasses 6 and 8 , we focused our investigation on the five other overpasses. In Figures 7 and 8, MWR retrievals assume a cloud effective radius of $8 \mu \mathrm{m}$ (the blue lines); lower and upper limits for MWR values, corresponding to a change in droplet effective radius from 6 to $14 \mu \mathrm{m}$, are denoted by gray bands.

[31] Retrievals from MWR, MFRSR, and AERONET agree well for Terra overpass 1 (Figure 7a). All AERONET retrievals fall into the range of MWR retrievals, and 3 out of 4 AERONET points are close to the MWR blue line. This result suggests that these clouds have an effective radius of $\sim 8 \mu \mathrm{m}$, nearly equal to the MODIS retrieval $(\sim 8.5 \mu \mathrm{m})$ in the closest pixel. For Terra overpass 2 , Figure $7 \mathrm{~b}$ shows that AERONET cloud optical depths decrease from 40 to 10 during the hour, while MWR retrievals also have a decreasing tendency but the AERONET retrievals are far below the blue line suggesting an effective radius of 12 $14 \mu \mathrm{m}$ rather than $8 \mu \mathrm{m}$. Remarkably, this inference agrees well the MODIS retrieval $(\sim 15 \mu \mathrm{m})$ in the closest pixel. Note that MFRSR optical depths (red line) fail to capture the temporal tendency (as shown by a flat curve) with an average of $\sim 25$. For Aqua overpass 1 (Figure 7c), AERONET retrievals are closest to MWR retrievals, which assume a $10 \mu \mathrm{m}$ effective radius and are again consistent with the MODISretrieved radius. In short, our AERONET optical depths compare well for these overpasses based on the good agreement with MWR retrievals and the consistency with MODIS effective radius retrievals.
[32] Results from Aqua overpasses 2 and 10 (Figure 8) are much more difficult to interpret. For both overpasses, sky images (not shown) show completely overcast clouds, and thus, we believe that MFRSR retrievals are reliable in these cases. However, MFRSR and MWR retrievals show almost no overlap except during 18.5-18.8 UTC of overpass 2 (Figure 8a). MODIS retrievals are closer to MFRSR retrievals in one case but closer to MWR retrievals in the other. AERONET retrievals agree better with those from MFRSR, which is promising, except for an outlier around 18.8 UTC in overpass 2. For that outlier, $1 \mathrm{~s}$ retrievals from the ARM shortwave spectrometer (SWS) were close to the AERONET results. The SWS has a very narrow FOV $\left(1.4^{\circ}\right)$. Therefore, we are confident that this outlier represents overhead cloud inhomogeneity that is smeared out in data taken from the MFRSR, which has a substantially larger FOV.
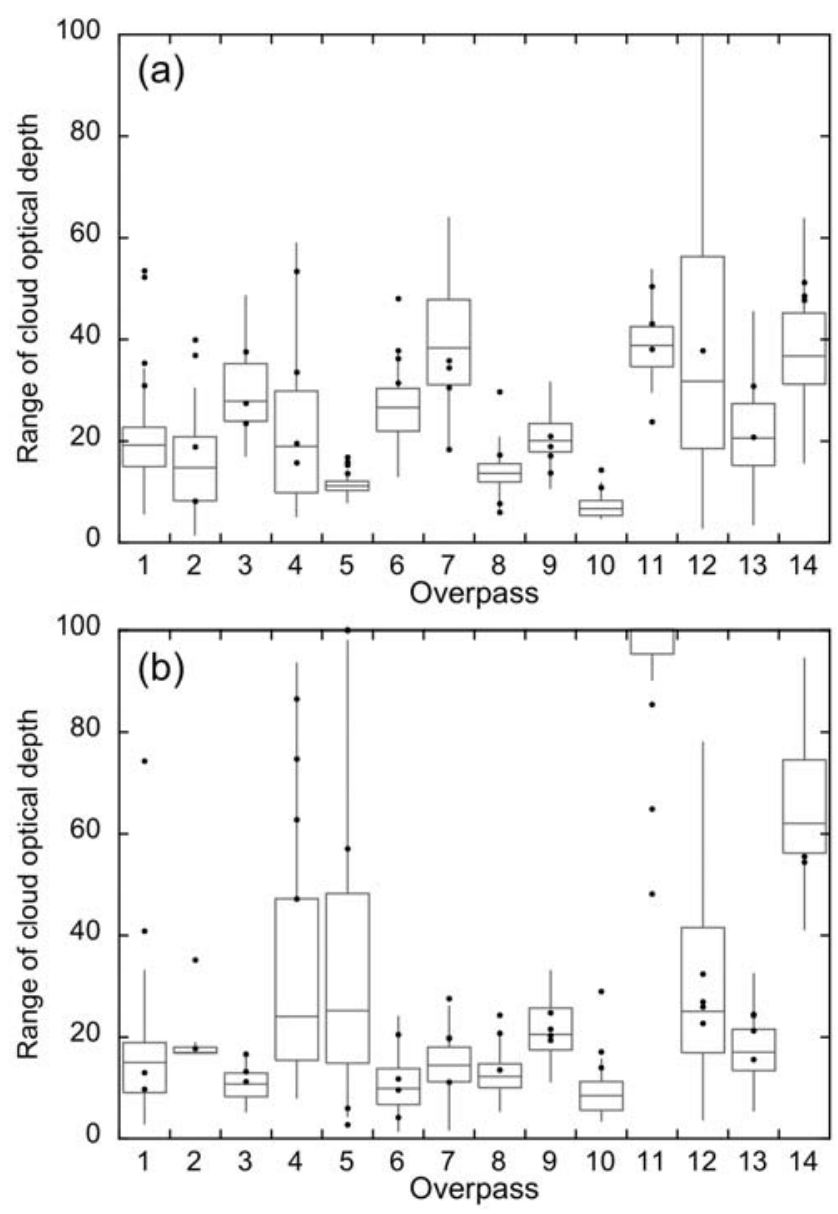

Figure 6. Box plots of cloud optical depths retrieved from MODIS (a) Terra and (b) Aqua overpasses in 2007. Information for each overpass can be found in Tables 1 and 2 . The bottom and top of each box represent the $25 \%$ and $75 \%$ quartiles, and the line inside the box represents the median [Tukey, 1977, p. 41-43]. The whiskers mark the "accepted range," which represents the farthest points that are not outliers (i.e., points within 1.5 times the interquartile distance). Coplotted dots represent AERONET 1.5 min average cloud optical depths during the $1 \mathrm{~h}$ time window centered at the MODIS overpass time. 

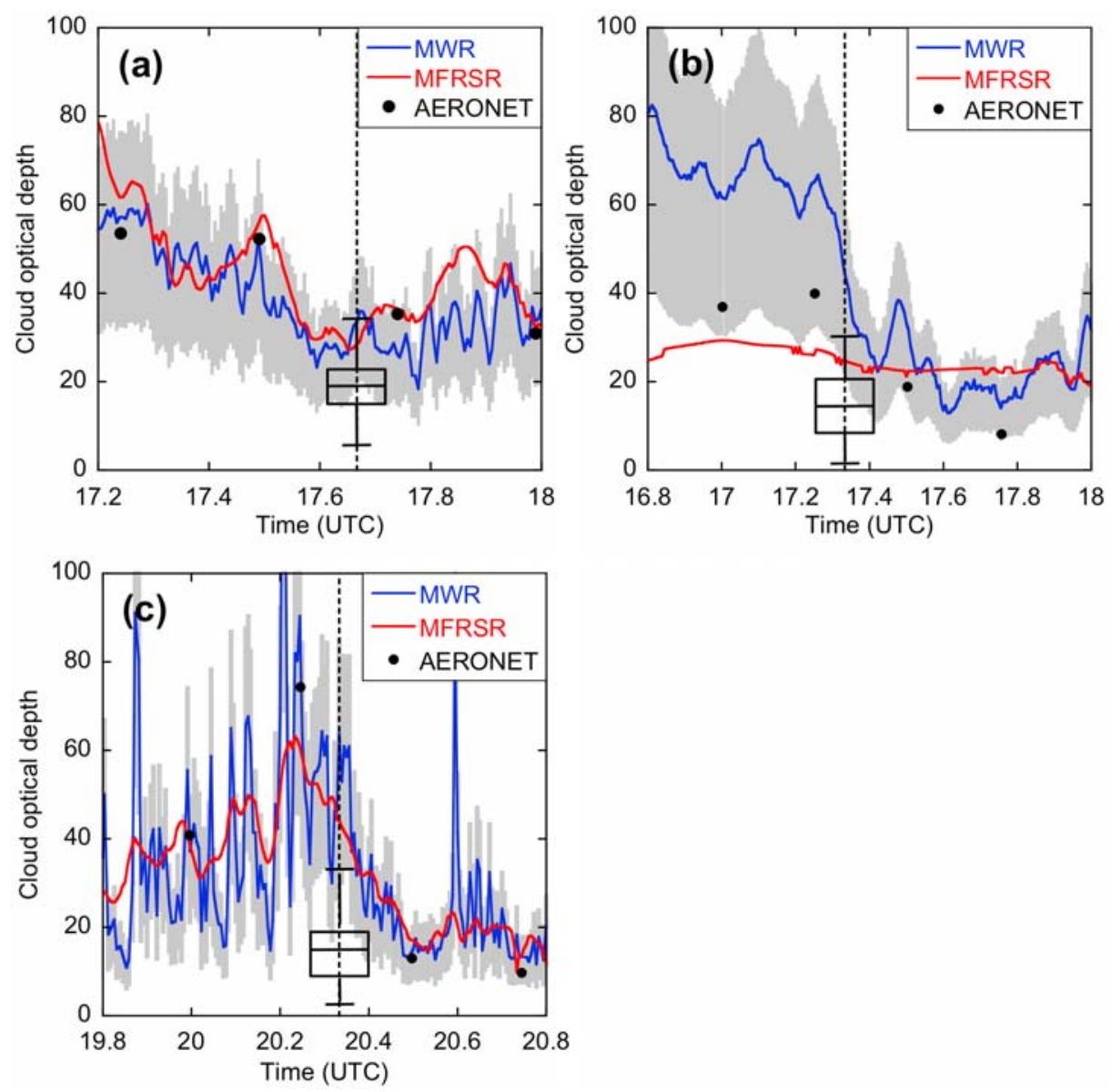

Figure 7. Retrieved cloud optical depth at the Oklahoma site for (a) 15 May 2007, (b) 26 May 2007, and (c) 5 May 2007 (corresponding to Terra overpass 1 and 2 in Table 1 and Aqua overpass 1 in Table 2, respectively). Black dots and red lines are retrievals from AERONET and ARM MFRSR, respectively. Retrievals from the ARM microwave radiometer (blue lines) assume a cloud effective radius of $8 \mu \mathrm{m}$; lower and upper limits for MWR values, corresponding to a change in droplet effective radius from 6 to $14 \mu \mathrm{m}$, are denoted by gray bands. Box plots represent statistics of MODIS retrievals (see Figure 6); the overpass time is denoted by the dashed lines.
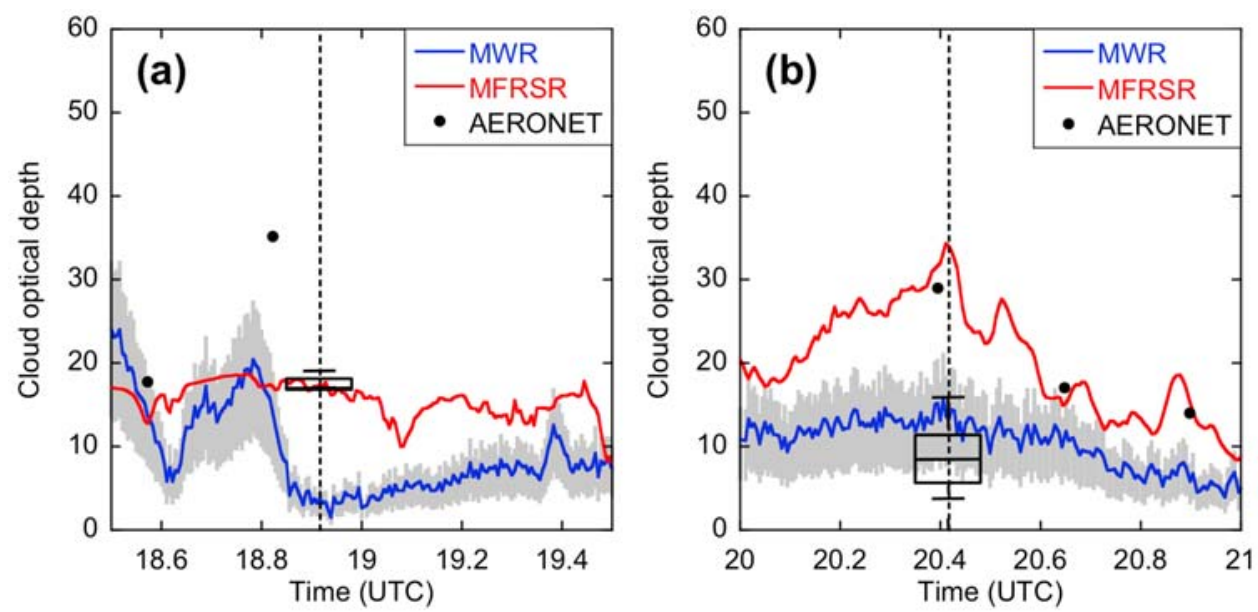

Figure 8. Same as Figure 7, but for (a) 20 June 2007 and (b) 6 December 2007 (Aqua overpasses 2 and 10 in Table 2, respectively). 


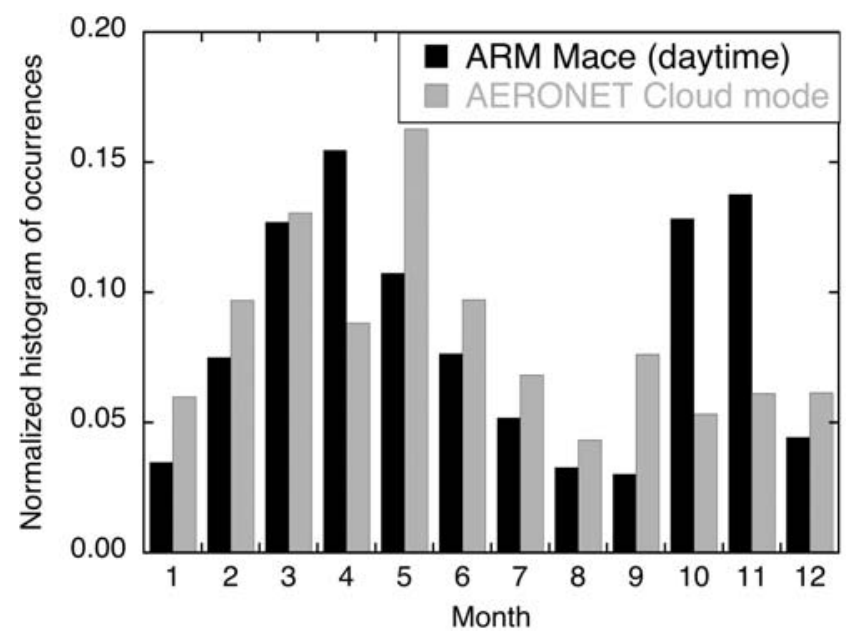

Figure 9. Normalized histogram of occurrence for overhead cloudiness at the ARM Oklahoma site. Black bars represent occurrences of Mace's retrievals during years 2002-2004, while gray bars represent occurrences of AERONET retrievals during November 2004 to June 2008.

\subsection{Three Year Cloud Climatology}

[33] We now look at the statistics of cloud optical depth over a 3 year period. For comparison, we use a data set of Mace et al. [2006], available in the ARM Archive, which characterizes cloud optical and microphysical properties at a time resolution of $5 \mathrm{~min}$ and a vertical resolution of $90 \mathrm{~m}$. The properties were estimated by merging radiosonde soundings, microwave radiometer, and cloud radar. In Mace's data set, cloud optical depth is derived from liquid water path and retrieved droplet size (equation (2)). Therefore, the uncertainty in cloud optical depth depends on the quality of liquid water path retrievals from the microwave radiometer and on the uncertainty in droplet size derived from empirical relationships.

[34] Data were excluded from comparison based on several factors. First, we excluded nighttime retrievals from Mace's data set. Next we excluded periods when rain gauge data showed nonzero rain rate and periods when the window of the microwave radiometer was wet, making liquid water path retrievals unreliable. Even with these exclusions, Mace's data set showed unphysically large optical depth (over 500) in some cases. To be conservative, we also excluded cases with total cloud optical depth values greater than 80. Furthermore, we excluded cases of low total optical depth values for two reasons. First, for clouds with optical depths less than 5, Mace et al. found significant discrepancies between their retrievals and those from MFRSR direct beam transmittance. Second, we examined optical depths retrieved from AERONET at the ARM Oklahoma site and found that the AERONET radiometer operates in normal aerosol mode when optical depth is less than about 3 . Therefore, we chose a threshold of 3 .

[35] Cloud mode data at the ARM site used here were collected during November 2004 to June 2008. The data interval is 3.7 years, but because of gaps due to off-site calibrations, this data record is about 3 years in length. We attempted to use Mace's retrievals during the same time period. Unfortunately, Mace's data set in the ARM archive is only available through December 2004. Therefore, we used their retrievals during years 2002-2004 to derive 3 year statistics. We realize this is not ideal, and in particular exposes us to issues of interannual variability in cloudiness, but at least it brings us close to the world of climatological studies.

[36] Figure 9 shows a normalized histogram of occurrence frequencies for overhead cloudiness for Mace's and for AERONET retrievals. Both data sets reveal that nonprecipitating cloud occurrence gradually increases from winter to spring, decreases in summer, and increases again in fall. Although the seasonal tendencies from the two data sets are similar, AERONET retrievals seem to miss the high occurrence in April, October, and November observed in Mace's retrievals. We are unable to say whether these are real differences or just a consequence of interannual variability.

[37] Figure 10 displays monthly normalized histograms of retrieved optical depth summed over 3 years. The plot shows that the AERONET retrievals behave consistently from month to month. Generally, the most frequent cloud optical depth values from AERONET are larger than those from Mace's data set by 5-10 optical depth units, with exceptions in March and November. In addition, the tails of the two histograms can be quite different, especially in January and December where there is a significant occurrence of AERONET retrievals between 40 and 60; these large values are far less prevalent in Mace's retrievals, but the AERONET retrievals are consistent with those from MFRSR and MWR during these months.

[38] Figure 11a shows a time series of monthly average cloud optical depth with one standard deviation marked. A striking result in both data sets is the remarkably small range of monthly mean optical depth (roughly 20 to 30) across the full annual cycle. AERONET monthly means are generally larger than those of Mace's retrievals. Monthly mean differences range between 0 and 9 with an average difference of 4 optical depths. The plot also shows that the standard deviations for these two data sets are similar and have little seasonal variation.

[39] The discrepancy in monthly optical depth between the two data sets could have several causes. First, as mentioned in our discussion of the broken cloud case, the current observation strategy excludes thin clouds. Second, these two data sets have different time-averaging windows: $1.5 \mathrm{~min}$ is used in this study, while Mace et al. [2006] used 5 min. Third, these two data sets represent climatology from different years.

[40] Overall, intercomparison of a 3 year climatology shows that (1) AERONET cloud mode tends to retrieve higher optical depth values more frequently than ARM's cloud radar retrievals and (2) AERONET retrievals have a lack of values ranging between 3 and 10 (Figure 11b). Agreement between the two data sets might be improved if AERONET cloud mode were to have a better observation strategy, for example, by always taking cloud observations after finishing an aerosol observational sequence, which could substantially compensate for the lack of thin cloud measurements.

\section{Summary}

[41] The Aerosol Robotic Network, composed of over 250 narrow field-of-view Sun/sky radiometers, has provided 

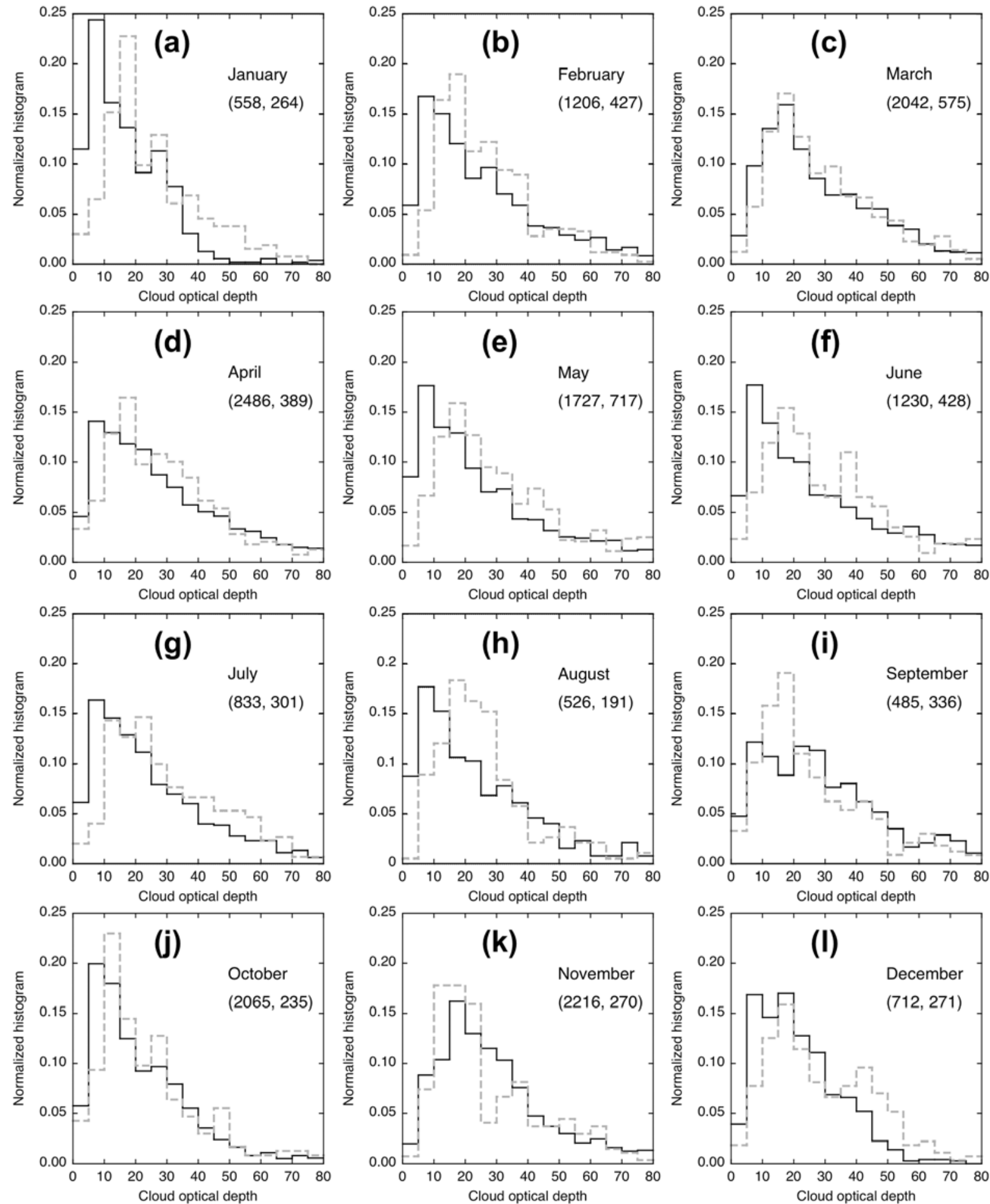

Figure 10. Monthly normalized histograms of retrieved cloud optical depths over 3 years, from ARM Mace's (black solid lines) and AERONET data sets (gray dashed lines). Bin sizes are 5 optical depth units. Figures 10a through 101 represent different months from January to December. Numbers in parenthesis represent the monthly occurrence for overhead cloudiness.

routine measurements of aerosol microphysical and optical properties for 15 years. These data are essential in the study of aerosol direct and indirect forcing on our climate system. However, when clouds block the Sun, Sun/sky radiometers are put to sleep to avoid cloud-contaminated radiance measurements. This paper presents a new observation strategy for the network, called cloud mode, which takes advantage of instrument idle time to observe clouds. This 

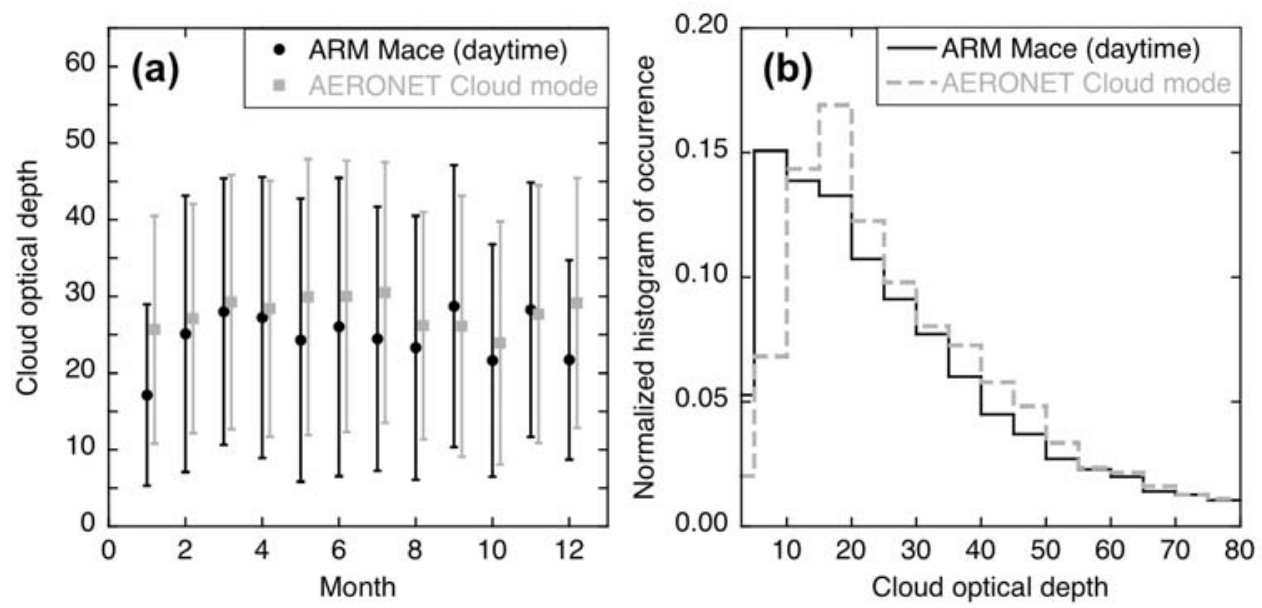

Figure 11. (a) Plot of the monthly average cloud optical depth with one standard deviation, and (b) normalized histogram of cloud optical depth using AERONET cloud mode retrievals during November 2004 to June 2008 and ARM Mace's retrievals during years 2002-2004.

cloud mode could inexpensively yet dramatically increase the global coverage of cloud optical depth observations.

[42] During cloud mode operations, AERONET radiometers take 10 zenith radiance measurements in up to 6 narrow spectral bands with a sampling resolution of $9 \mathrm{~s}$. This set of measurements is taken every $15 \mathrm{~min}$, except when the radiometer finds the Sun and does an aerosol observation sequence. We used zenith radiances at wavelengths of 440 and $870 \mathrm{~nm}$ to retrieve cloud optical depth. Cloud optical depths are almost identical at those two wavelengths, but vegetated surfaces reflect differently, the surface is typically 5-8 times brighter at $870 \mathrm{~nm}$ than at $440 \mathrm{~nm}$. For operational purposes: we use surface albedo from the MODIS Terra/ Aqua combined product that is closest in time. When this product is not available, we use a climatological database derived from MODIS year 2000-2004 observations. In general, our retrieval method is weakly sensitive to the uncertainty in surface albedo estimates.

[43] We examined two types of cloud optical depth in this paper: instantaneous and $1.5 \mathrm{~min}$ average. Instantaneous cloud optical depth is derived from individual zenith radiance measurements, and the $1.5 \mathrm{~min}$ average is derived from the cluster of 10 instantaneous retrievals, which will be reported in the AERONET Archive. These optical depth values were evaluated by comparing them to those retrieved from other ground-based benchmark instruments and to MODIS cloud products over the ARM Oklahoma site for a variety of cloud fields.

[44] For a case in which cloud fields changed between clear-sky, small cumulus, and overcast clouds, we compared our AERONET retrievals to those from ARM's microwave radiometer. We found that both instantaneous and $1.5 \mathrm{~min}$ average optical depths capture the rapid change of cloud evolution and advection; they agree well with those retrieved from microwave data by assuming an effective drop radius of $8 \mu \mathrm{m}$.

[45] We also analyzed overcast cases in 2007. Results show that AERONET instantaneous and $1.5 \mathrm{~min}$ average optical depth values agree with those from the MFRSR radiative flux method better than $20 \%$ and $15 \%$, respectively. In addition, intercomparison with MODIS cloud optical depths shows that $70 \%-80 \%$ of AERONET retrievals fall into the accepted range of MODIS values. Overall, the intercomparison results are encouraging but show the difficulty of comparing satellite and surface retrievals. We are confident that the comparison would be improved if AERONET cloud mode observations were made more frequently.

[46] Furthermore, 3 year statistics derived from AERONET 1.5 min average cloud optical depths were compared to those from ARM Mace's 5 min averages. Both data sets demonstrate that nonprecipitating clouds occurred more frequently in springtime, but a second peak in fall shown in ARM Mace's retrievals is not seen in AERONET retrievals. A striking result in both data sets is the remarkably small range of monthly mean cloud optical depth (roughly 20 to 30) across the full annual cycle. Monthly means from the two data sets also have similar seasonal trends and standard deviation. However, AERONET monthly means tend to be larger than Mace's by several optical depth units. This bias can be reduced if AERONET cloud mode observations were made more frequently after finishing an aerosol observing sequence.

[47] Finally, the studies of aerosol-cloud interactions with AERONET data, such as that of Koren et al. [2007], used binary information about clouds (i.e., clouds versus no clouds) to relate aerosol optical depth to the time passed from the last cloud. Additional AERONET cloud modecloud mode data will allow for differentiation between low thick clouds and high thin clouds. These dynamic AERONET cloud mode data will greatly improve the accuracy of aerosol-cloud interaction studies.

[48] Acknowledgments. This research was supported by the Office of Science (BER, US Department of Energy, Interagency agreement DE-AI02-08ER64562, DE-FG02-08ER64563, DE-FG02-08ER54564) as part of the ARM program. We also thank the AERONET team for providing instrument calibration, deployment, and data processing. 


\section{References}

Andreae, M. O. (2009), Correlation between cloud condensation nuclei concentration and aerosol optical thickness in remote and polluted regions, Atmos. Chem. Phys., 9, 543-556.

Barker, H. W., and A. Marshak (2001), Inferring optical depth of broken clouds above green vegetation using surface solar radiometric measurements, J. Atmos. Sci., 58, 2989-3006.

Barker, H. W., A. Marshak, W. Szyrmer, A. Trishchenko, J. P. Blanchet, and Z. Li (2002), Inference of cloud optical depth from aircraft-based solar radiometric measurements, J. Atmos. Sci., 59(13), 2093-2111.

Bender, F., H. Rodhe, R. Charlson, A. Ekman, and N. Loeb (2006), 22 views of the global albedo-comparison between 20 GCMs and two satellites, Tellus, 58A, 320-330.

Box, M. A., S. A. W. Gerstl, and C. Simmer (1988), Application of the adjoint formulation to the calculation of atmospheric radiative effects, Beitr. Phys. Atmos., 61, 303-311.

Chiu, J. C., A. Marshak, Y. Knyazikhin, W. Wiscombe, H. Barker, J. C. Barnard, and Y. Luo (2006), Remote sensing of cloud properties using ground-based measurements of zenith radiance, J. Geophys. Res., 111, D16201, doi:10.1029/2005JD006843.

Clothiaux, E. E., T. P. Ackerman, G. G. Mace, K. P. Moran, R. T. Marchand, M. A. Miller, and B. E. Martner (2000), Objective determination of cloud heights and radar reflectivities using a combination of active remote sensors at the ARM CART sites, J. Appl. Meteorol., 39, 645-665.

Crewell, S., and U. Löhnert (2003), Accuracy of cloud liquid water path from ground-based microwave radiometer. 2. Sensor accuracy and synergy, Radio Sci., 38(3), 8042, doi:10.1029/2002RS002634.

Hall, D. K., G. A. Riggs, V. V. Salomonson, N. E. Di Girolamo, and K. J. Bayr (2002), MODIS snow-cover products, Remote Sens. Environ., 83, 181-194.

Holben, B. N., et al. (1998), AERONET: A federated instrument network and data archive for aerosol characterization, Remote Sens. Environ., $66,1-16$.

Illingworth, A. J., et al. (2007), Cloudnet: Continuous evaluation of cloud profiles in seven operational models using ground-based observations, Bull. Am. Meteorol. Soc., 88, 883-898.

Kikuchi, N., T. Nakajima, H. Kumagai, H. Kuroiwa, A. Kamei, R. Nakamura, and T. Y. Nakajima (2006), Cloud optical thickness and effective particle radius derived from transmitted solar radiation measurements: Comparison with cloud radar observations, J. Geophys. Res., 111, D07205, doi:10.1029/2005JD006363.

Kim, B.-G., S. E. Schwartz, M. A. Miller, and Q. Min (2003), Effective radius of cloud droplets by ground-based remote sensing: Relationship to aerosol, J. Geophys. Res., 108(D23), 4740, doi:10.1029/2003JD003721.

Koren, I., L. A. Remer, Y. J. Kaufman, Y. Rudich, and J. V. Martins (2007), On the twilight zone between clouds and aerosols, Geophys. Res. Lett., 34, L08805, doi:10.1029/2007GL029253.

Levy, R. C., L. A. Remer, and O. Dubovik (2007), Global aerosol optical properties and application to MODIS aerosol retrieval over land, J. Geophys. Res., 112, D13210, doi:10.1029/2006JD007815.

Li, Z. Q., M. C. Cribb, and A. P. Trishchenko (2002), Impact of surface inhomogeneity on solar radiative transfer under overcast conditions, J. Geophys. Res., 107(D16), 4294, doi:10.1029/2001JD000976.

Liljegren, J. C., and B. M. Lesht (1996), Measurements of integrated water vapor and cloud liquid water from microwave radiometer at the DOE ARM Cloud and Radiation Testbed in the Southern Great Plains, paper presented at International Geoscience and Remote Sensing Symposium, Inst. of Electr. and Electron. Eng., Lincoln, Neb, 21-26 May.

Liljegren, J. C., E. Clothiaux, G. G. Mace, S. Kato, and X. Q. Dong (2001), A new retrieval for cloud liquid water path using a ground-based microwave radiometer and measurements of cloud temperature, J. Geophys. Res., 106(D13), 14,485-14,500.

Mace, G. G., et al. (2006), Cloud radiative forcing at the atmospheric radiation measurement program climate research facility: 1. Technique, validation, and comparison to satellite-derived diagnostic quantities, J. Geophys. Res., 111, D11S90, doi:10.1029/2005JD005921.

Marchand, R., T. Ackerman, E. R. Westwater, S. A. Clough, K. CadyPereira, and J. C. Liljegren (2003), An assessment of microwave absorption models and retrievals of cloud liquid water using clear-sky data J. Geophys. Res., 108(D24), 4773, doi:10.1029/2003JD003843.

Marshak, A., Y. Knyazikhin, A. B. Davis, W. J. Wiscombe, and P. Pilewskie (2000), Cloud-vegetation interaction: Use of normalized difference cloud index for estimation of cloud optical thickness, Geophys. Res. Lett., 27(12), 1695-1698, doi:10.1029/1999GL010993.

Marshak, A., Y. Knyazikhin, K. D. Evans, and W. J. Wiscombe (2004), The "RED versus NIR" plane to retrieve broken-cloud optical depth from ground-based measurements, J. Atmos. Sci., 61, 1911-1925.

Myhre, G., et al. (2009), Modelled radiative forcing of the direct aerosol effect with multi-observation evaluation, Atmos. Chem. Phys., 9, 1365-1392.

Miller, M. A., K. L. Johnson, D. T. Troyan, E. E. Clothiaux, E. J. Mlawer, and G. G. Mace (2003), ARM value-added cloud products: description and status, Proceedings of the 13th ARM Science Team Meeting, 31 March to 4 April 2003, Broomfield, Colo. (Available at http://www. arm.gov/publications/proceedings/conf13/extended_abs/miller-ma.pdf)

Min, Q., and L. C. Harrison (1996), Cloud properties derived from surface MFRSR measurements and comparison with GOES results at the ARM SGP Site, Geophys. Res. Lett., 23(13), 1641-1644, doi:10.1029/ 96GL01488.

Moody, E. G., M. D. King, S. Platnick, C. B. Schaaf, and F. Gao (2005), Spatially complete global spectral surface albedos: Value-added data sets derived from Terra MODIS land products, IEEE Trans. Geosci. Remote Sens., 43, 144-158.

Moody, E. G., M. D. King, C. B. Schaaf, D. K. Hall, and S. Platnick (2007), Northern Hemisphere five-year average (2000-2004) spectral albedos of surfaces in the presence of snow: Statistics computed from Terra MODIS land products, Remote Sens. Environ., 111, 337-345.

Morcrette, J.-J., et al. (2009), Aerosol analysis and forecast in the European Centre for medium-range weather forecasts integrated forecast system: Forward modeling, J. Geophys. Res., 114, D06206, doi:10.1029/ 2008JD011235.

Remer, L., et al. (2005), The MODIS aerosol algorithm, products, and validation. J. Atmos. Sci., 62, 947-973.

Schaaf, C. B., et al. (2002), First operational BRDF, albedo nadir reflectance products from MODIS, Remote Sens. Environ., 83(1-2), 135-148. Sengupta, M., E. E. Clothiaux, T. P. Ackerman, S. Kato, and Q. Min (2003), Importance of accurate liquid water path for estimation of solar radiation in warm boundary layer clouds: an observational study, J. Climate, 16(18), 2997-3009.

Stamnes, K., S.-C. Tsay, W. J. Wiscombe, and K. Jayaweera (1988), Numerically stable algorithm for discrete-ordinate-method radiative transfer in multiple scattering and emitting layered media, Appl. Opt., 27, 2502-2512.

Stokes, G. M., and S. E. Schwartz (1994), The Atmospheric Radiation Measurement (ARM) Program: Programmatic background and design of the cloud and radiation test bed, Bull. Am. Meteorol. Soc., 75 1201-1221.

Tucker, C. J. (1979), Red and photographic infrared linear combination for monitoring vegetation, Remote Sens. Environ., 8, 127-150.

Tukey, J. W. (1977), Exploratory Data Analysis, 688 pp., Addison-Wesley, Reading, Mass.

Turner, D., et al. (2007), Thin liquid water clouds: Their importance and our challenge, Bull. Am. Meteorol. Soc., 88, 177-190.

Westwater, E. R., Y. Han, M. D. Shupe, and S. Y. Matrosov (2001), Analysis of integrated cloud liquid and precipitable water vapor retrievals from microwave radiometers during the Surface Heat Budget of the Arctic Ocean project, J. Geophys. Res., 106, 32,019-32,030, doi:10.1029/ 2000JD000055.

Zhang, M. H., et al. (2005), Comparing clouds and their seasonal variations in 10 atmospheric general circulation models with satellite measurements, J. Geophys. Res., 110, D15S02, doi:10.1029/2004JD005021.

J. C. Chiu, University of Maryland Baltimore County, Baltimore, MD 21250, USA. (christine.chiu@nasa.gov)

D. M. Giles and I. Slutsker, Sigma Space Corporation, Lanham, MD USA.

B. N. Holben, A. Marshak, and W. J. Wiscombe, NASA/Goddard Space Flight Center, Greenbelt, MD 20770-2548, USA.

C.-H. Huang, Science Systems and Applications, Inc., Lanham, MD 20706-6239, USA.

Y. Knyazikhin, Boston University, Boston, MA 02215, USA. 